قراءة في كتاب

منهج القرآن الكريم في التغيير الفردي* تأليف: تَالي عفيف يوسف جابر

عزيز البطيوي

يتناول هذا الكتاب قضية منهجية ومعرفية مثَّلت محور اهتمام مشروعات الإصلاح

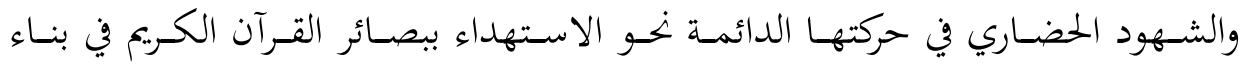

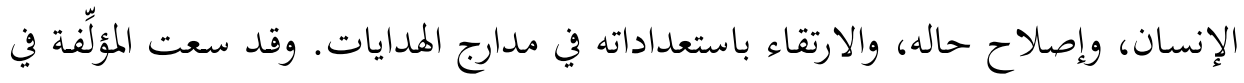

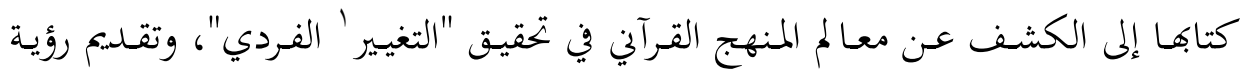

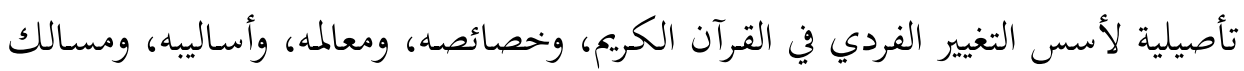

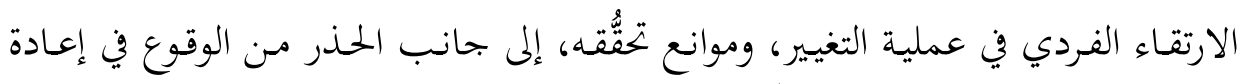

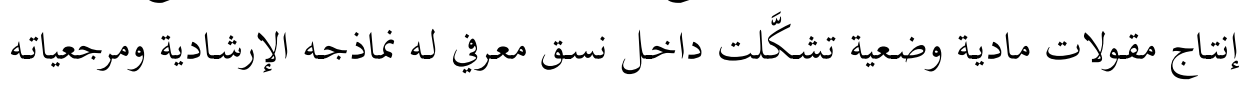

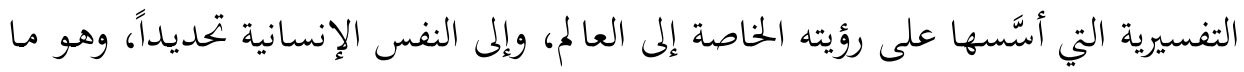

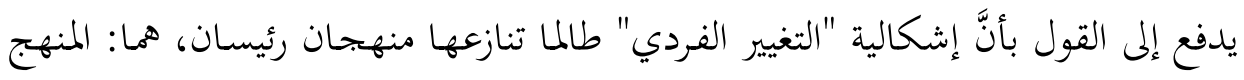

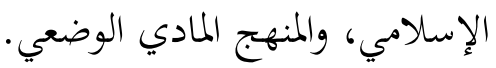

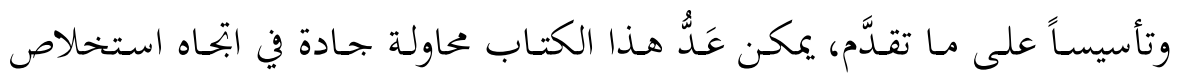

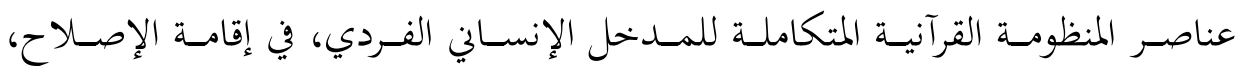

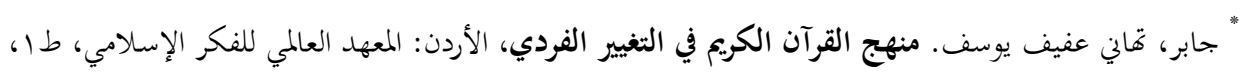

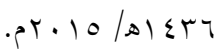
"' دكتوراه في التفسير وعلوم القرآن، كلية الشريعة، قسم أصول الدين، عنوان الرسالة: "دلالات القراءات القرآنية في

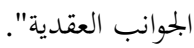

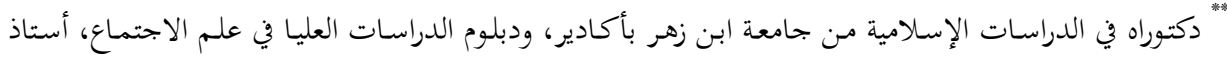

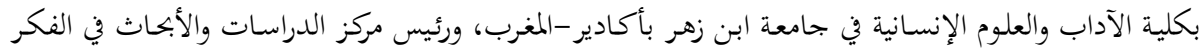

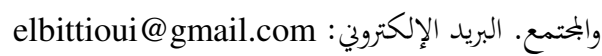

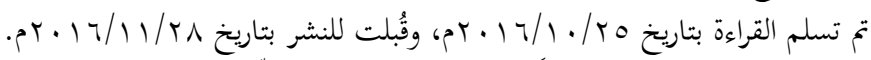

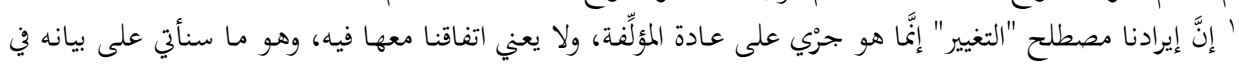

خائمة هذه المراجعة. 


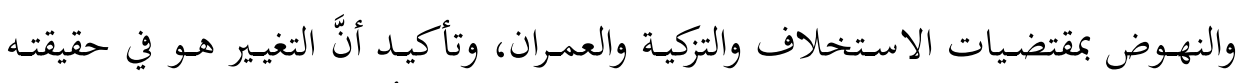

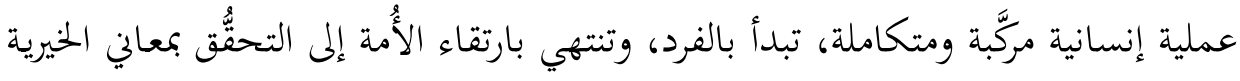

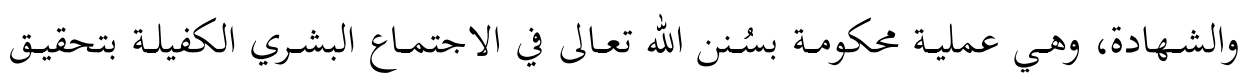

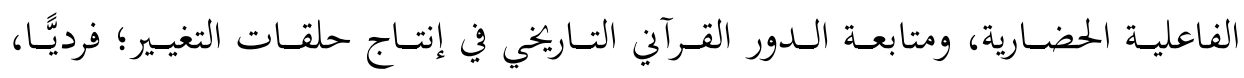
واجتماعيًّا.

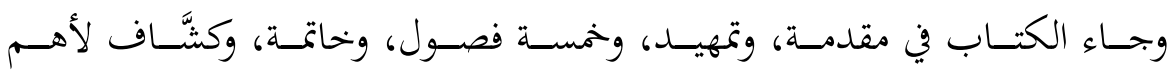

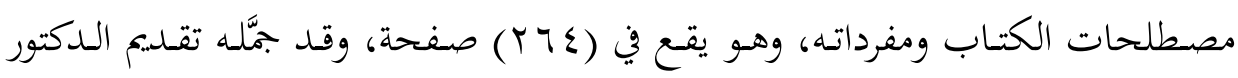

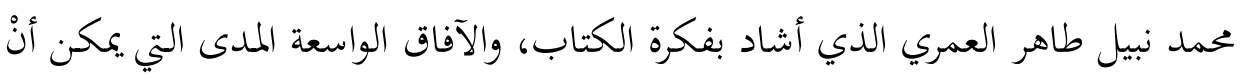
يفتحها أمام الباحثين، وكل مهموم بقضية إصلاح الفرد والبحتمع. وقــ صـدَّرت المؤلِّفـة أول فصـولها بعنـوان: "مسـتلزمات الدراسـة في موضـوع مـنهـج القرآن الكريم في التغيير الفردي"، فأوعبت في تناول معنى المنهج والتغيير لغةً واصطلاحاً.

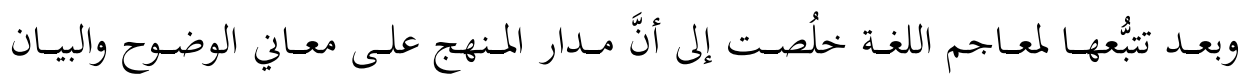

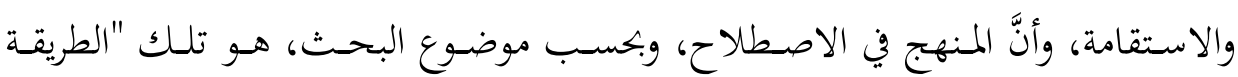

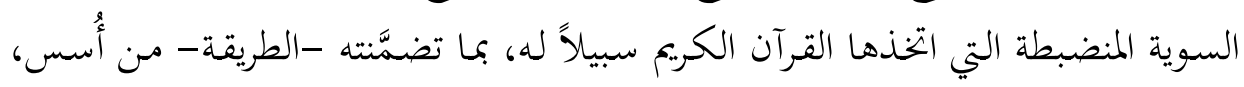
وما استخدمه القرآن من وسائل وأساليب، للوصول إلى أهدافه ومقاصده. وأبرزت الباحثة أيضًا توجُّه معاجم اللغة إلى تحديد دلالة التغيير بالتحويل والتبديل،

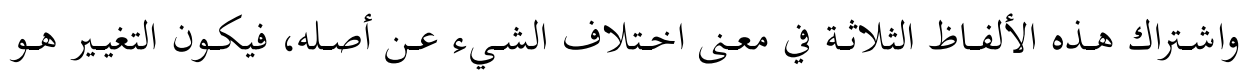

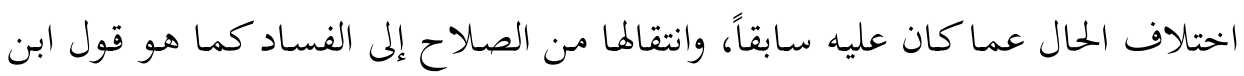

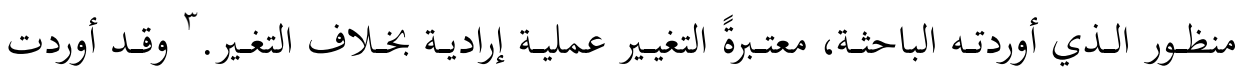

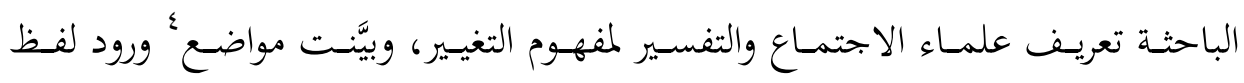

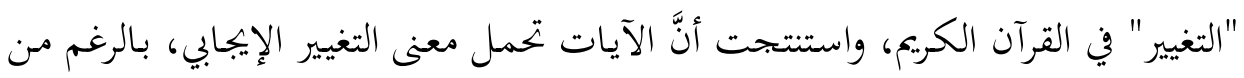

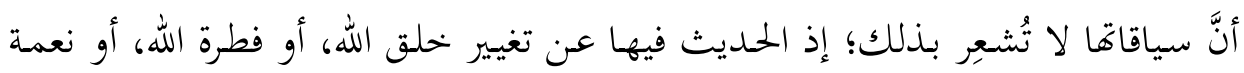

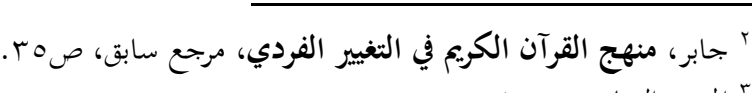

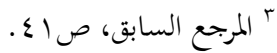

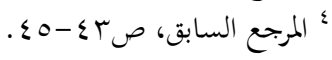




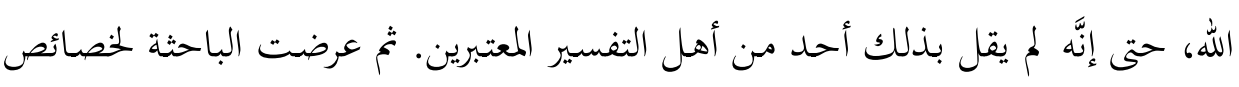

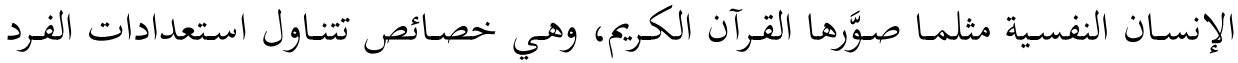

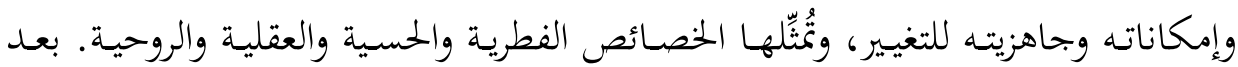

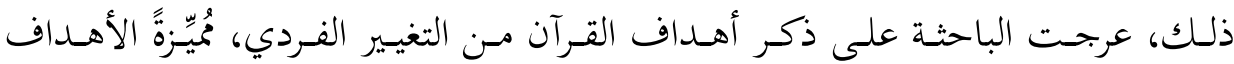

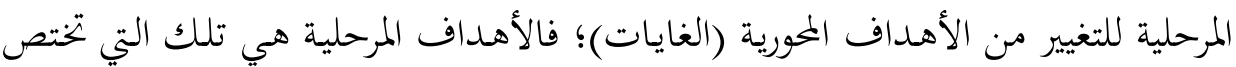

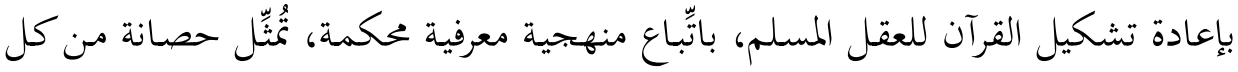

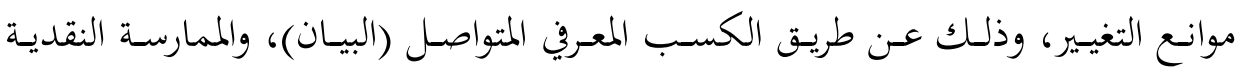

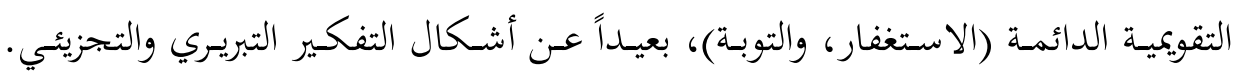

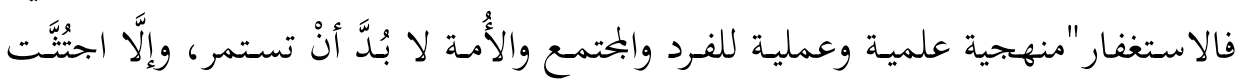

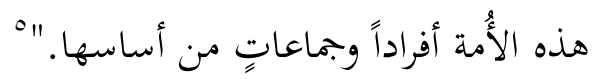

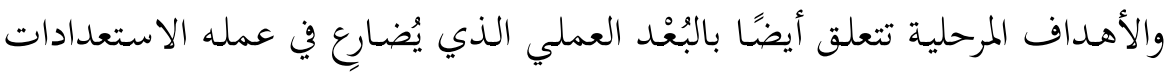
الفطرية والحسية والعقلية وتنمية القدرات الإرادية تنميةً تتكامل فيها مستويات الإرادة:

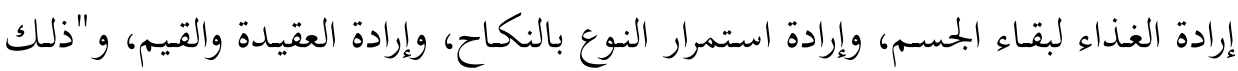

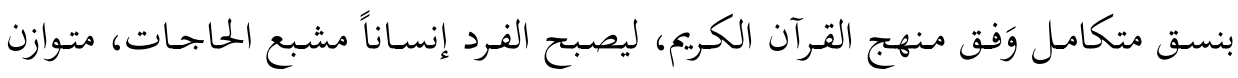

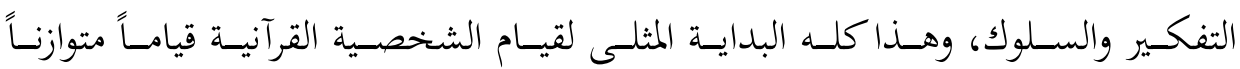

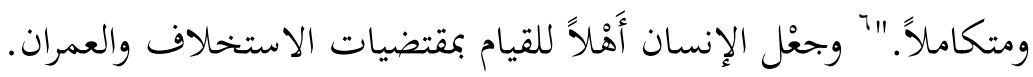

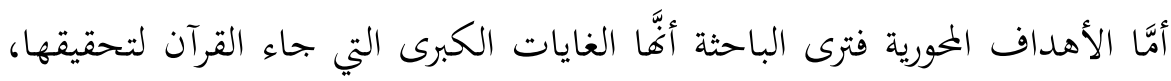

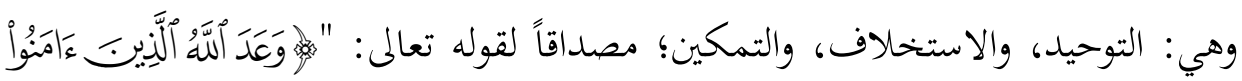

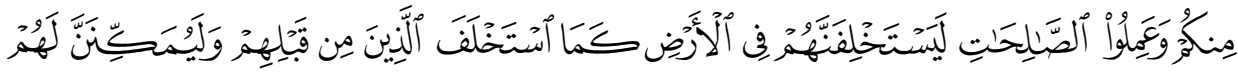

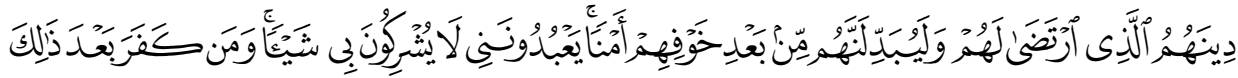

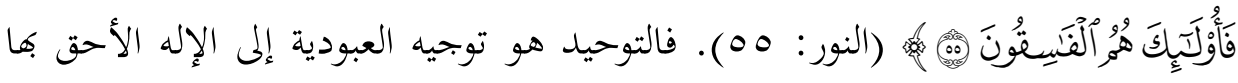

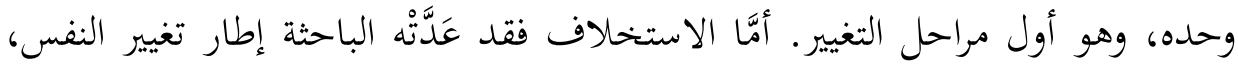
ووظيفة الإنسان في الأرض، وانعكاس ما في النفس على عمل الإنسان، وتجلي ذلك في التئي

$$
\begin{aligned}
& \text { ه المرجع السابق، ص ص } 9 .
\end{aligned}
$$

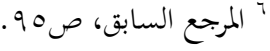




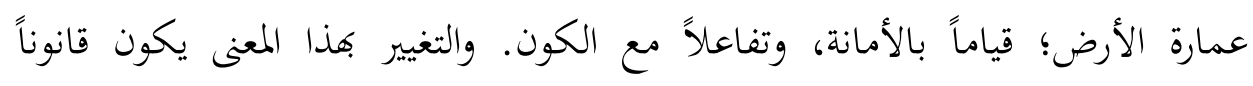

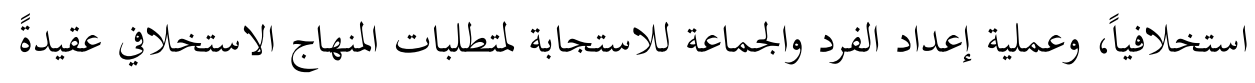

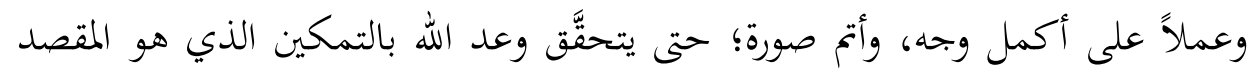

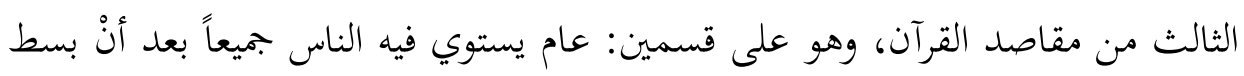

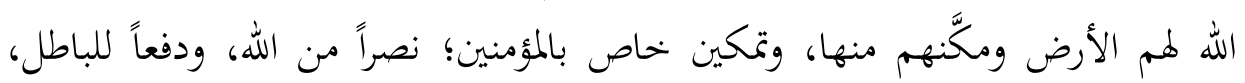

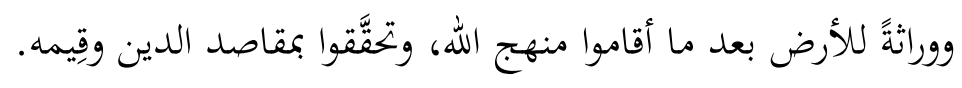

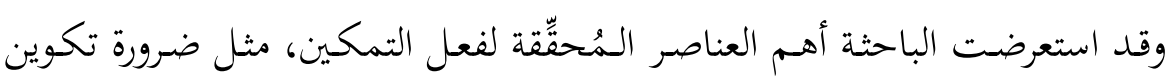

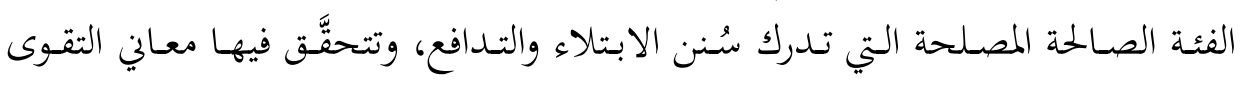

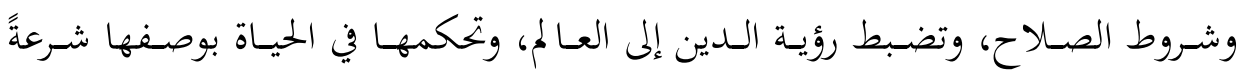

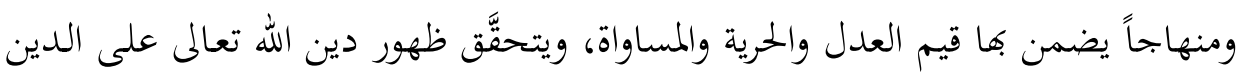

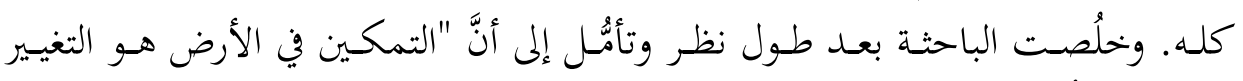

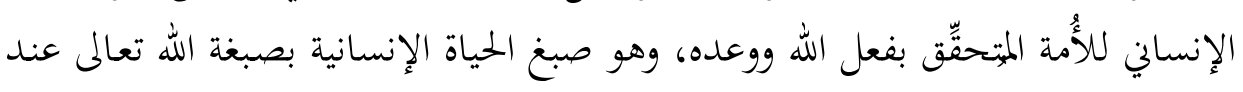

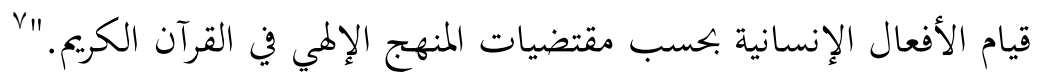

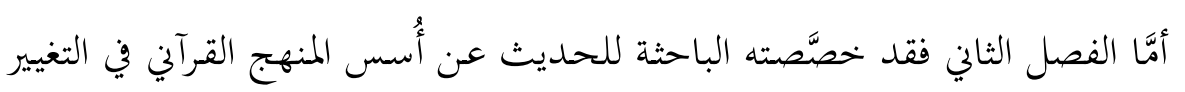

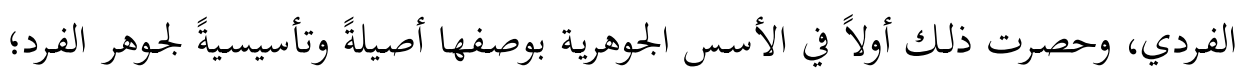

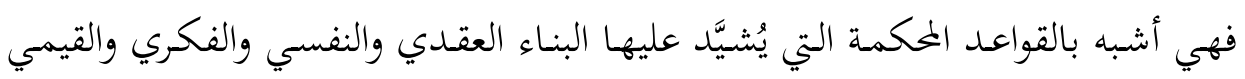

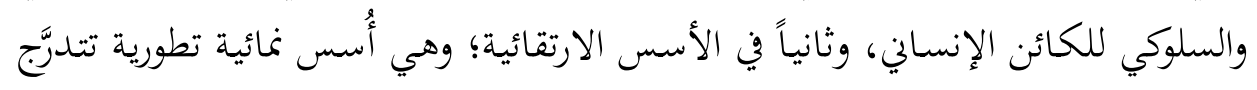

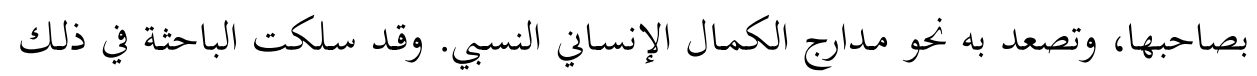

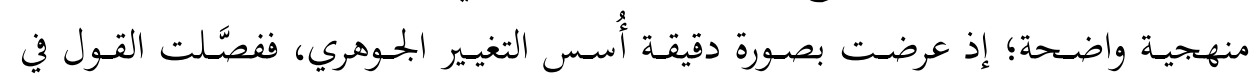

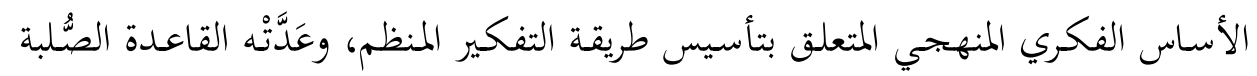

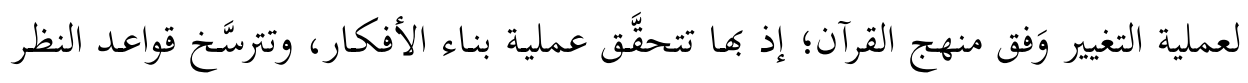

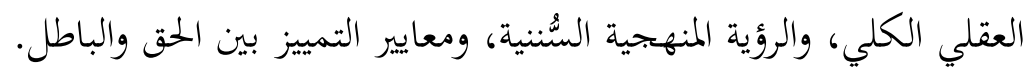

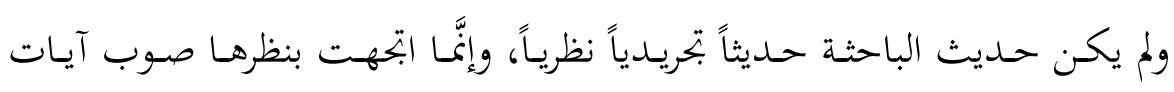

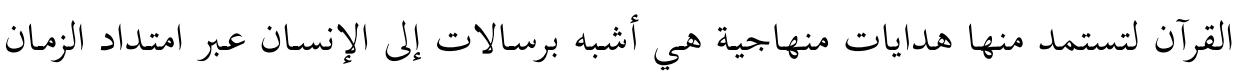




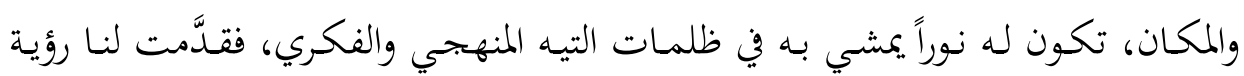

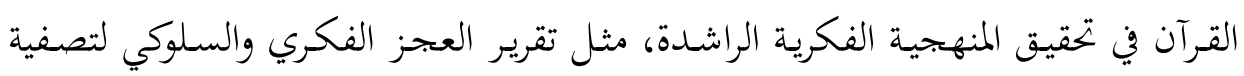

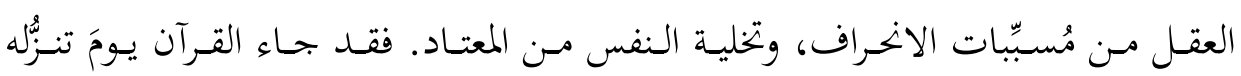

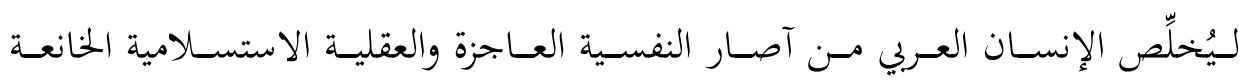

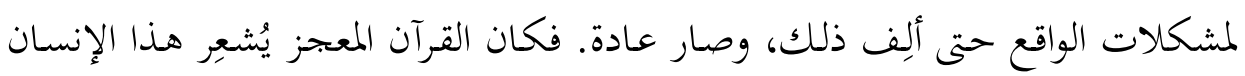

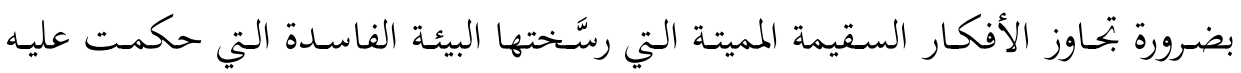

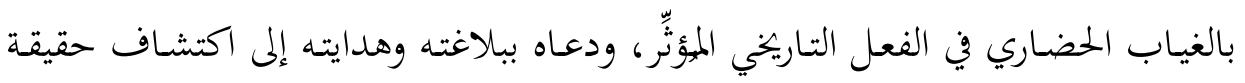

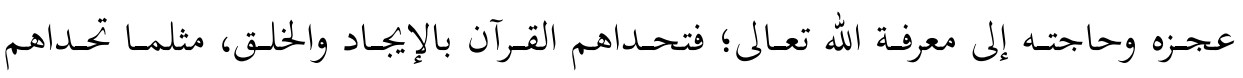

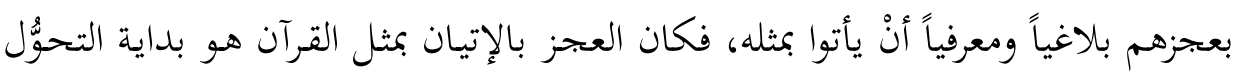

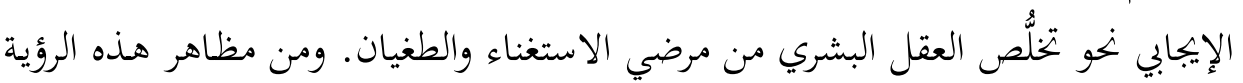

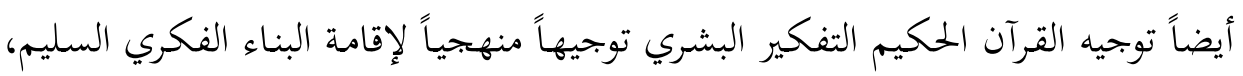
وقد استبطت الباحثة أهم القضايا الدالة على هذا التوجيه المنهجي القرآين:

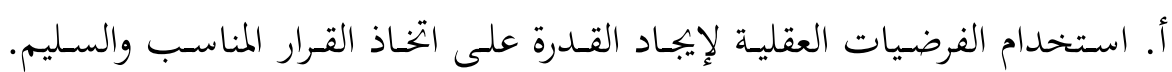

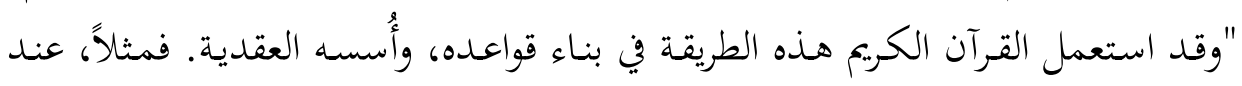

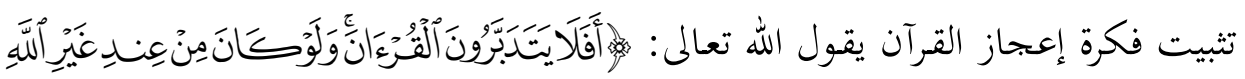

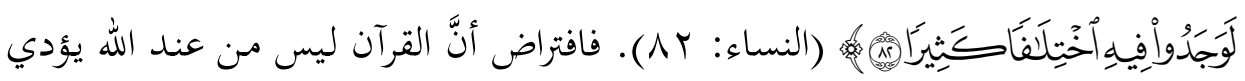

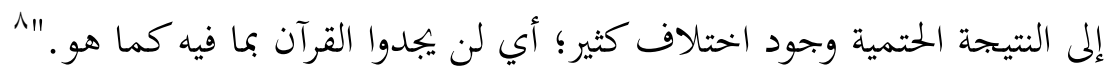
ولا شـكَّ في أنَّ هـا التوجيه المنهجي القرآين للتفكير البشري نهو الإمساك بمنهـج

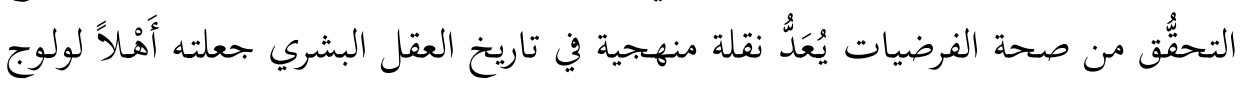

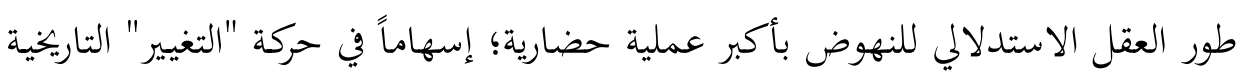
نغو الاستجابة لبصائر الوحي.

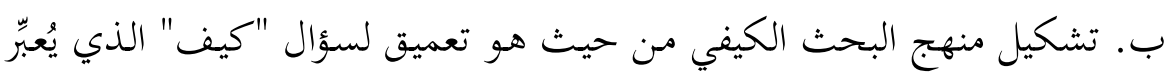

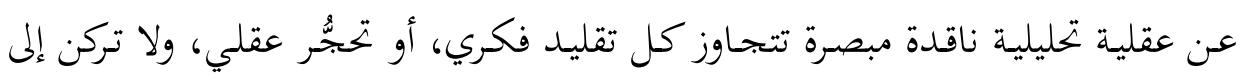




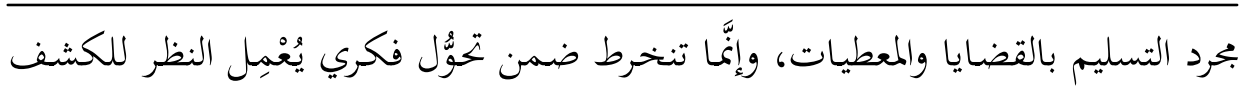

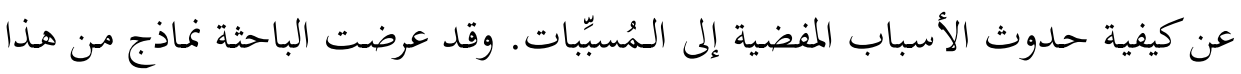

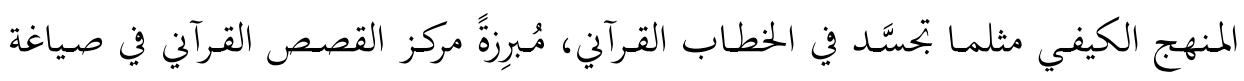

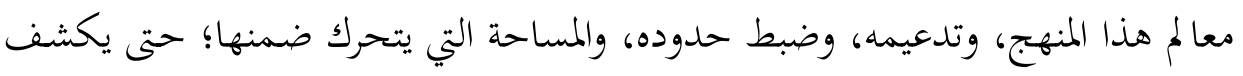

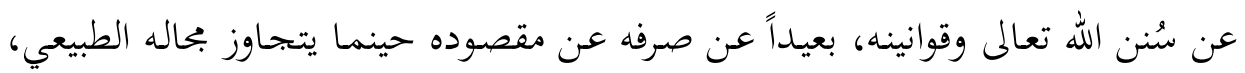
ويخوض في عـالم الغيـب والميتافيزيقـا. وختمـت الباحثـة بالضـبط المنهجي لإرادة الإنسـان

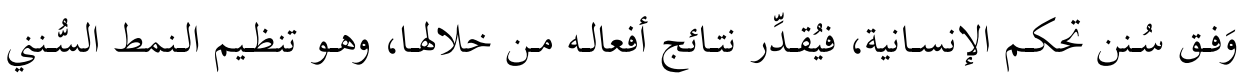
بوصفه ثالث قواعد بناء التفكير المنهجي وَفق المرجعية القرآنية التي أعادت تشكيل الإنيل العقل

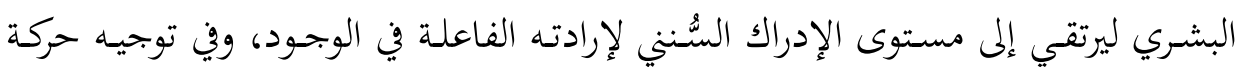
الحياة، بعيداً عن أيِّ نزعة جبرية استسلامية.

تم شرعت الباحثة في بيان الأسـاس الثاني مـن أسس التغيير الجموهري للفرد، الذي يتعلق ببناء التصور الاعتقادي السليم عن الذات الإلهية، بوصفه الأساس الأهم في عملية

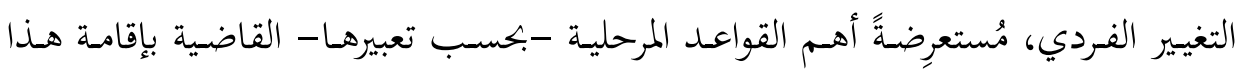

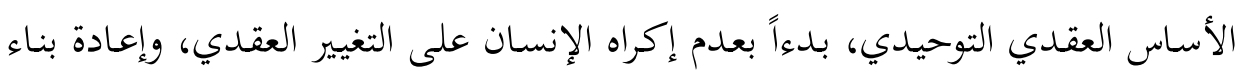

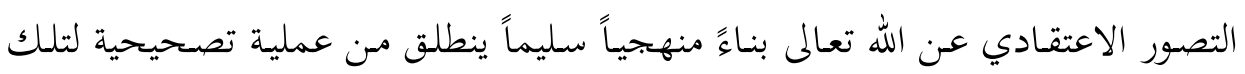
الانحرافات التي علت العقل البشري، فأودت به في أودية الشرك والوثنية، ويستكمل ذلك نكالك بترسيخ البناء المعرفي عن حقائق الذات الإلهية، وصفاها، والإيمان بها؛ تعظيماً لها، وافتقاراً إليها، والتزاماً بأوامرها، فتستقر في جوهر الفرد حتى تخرجه من داعية هواه. وتمضي الباحثة في هذا الفصل باسطةً أُسس المنهج القرآي في التغيير الارتقائي لبلوغ

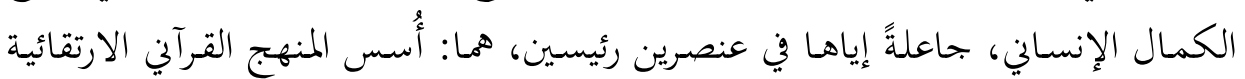

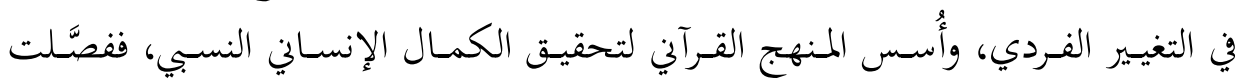

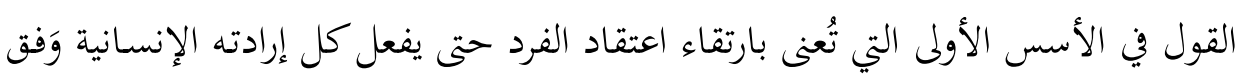

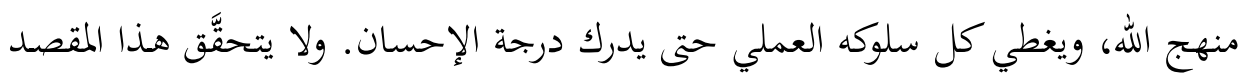
العظيم إلا بالعمل بالتزامات هي أشبه بكليات منظمة للحياة؛ أولها: قيمة التكريم الإلهي 
للإنسان والإلزام برعاية هذه الكرامة وما يستتبعها من قيم العدل والمساواة، وثانيها: سمو

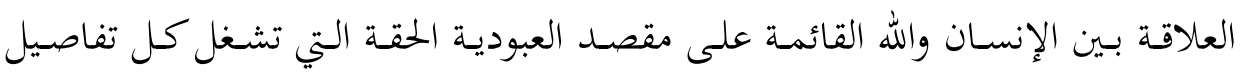

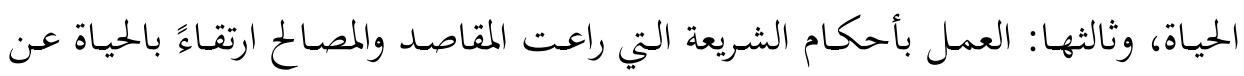

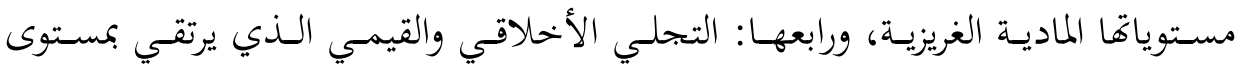
العلاقات الإنسانية إلى تعميق الإحساس بالمسؤولية الفردية بحاه الجماعة بأداء الحقوق.

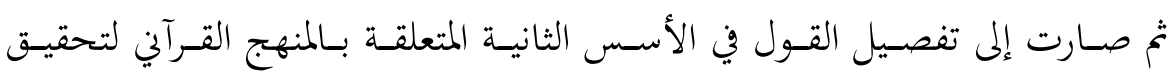

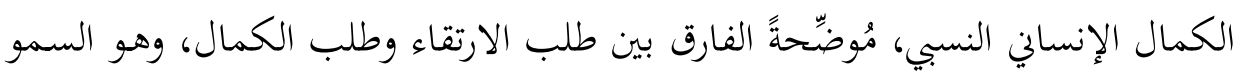

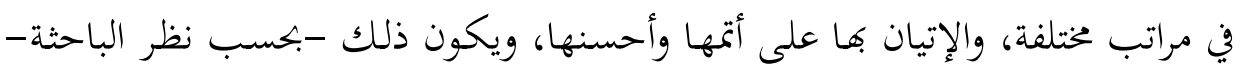

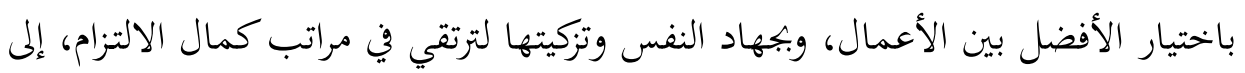

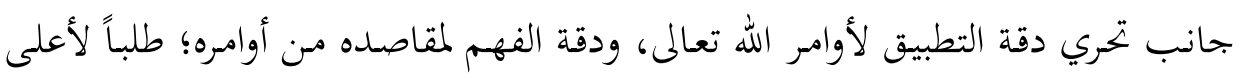

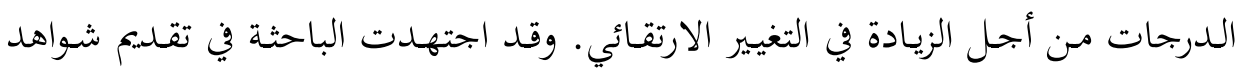

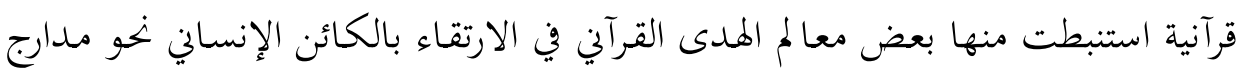
الكمال النسبي. واستنبطت الباحثة في الفصل الثالث أسـاليب القـرآن الكريم المنهجيـة والتنفيذية

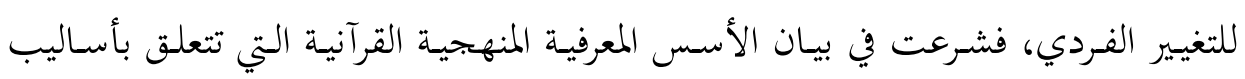

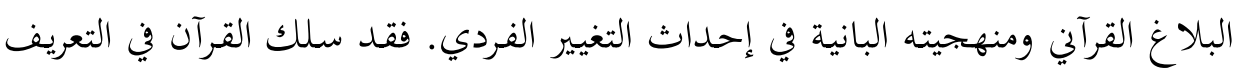

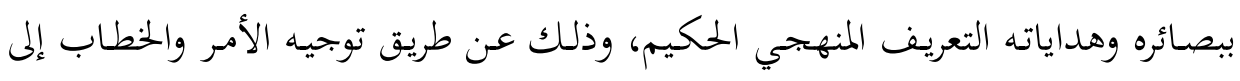

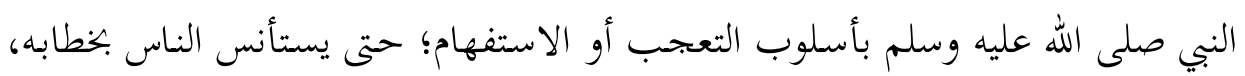

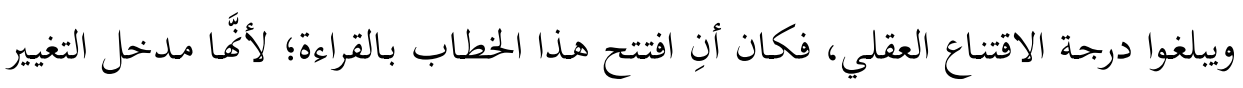

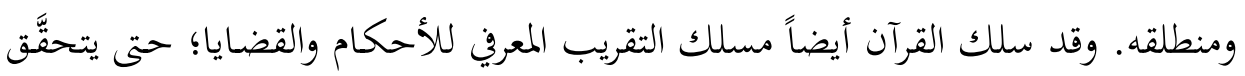

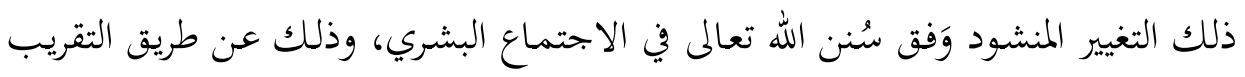

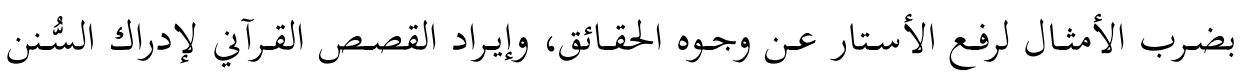

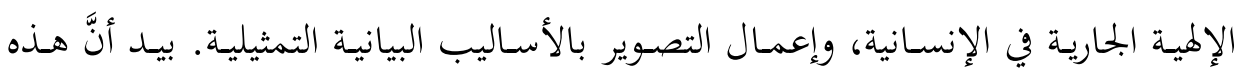




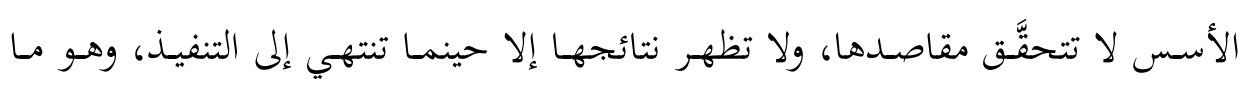

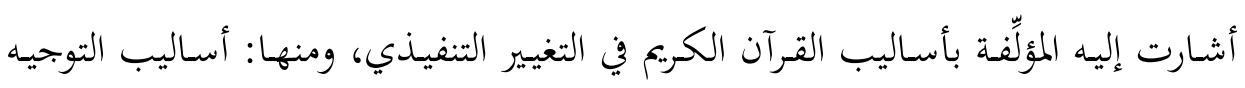

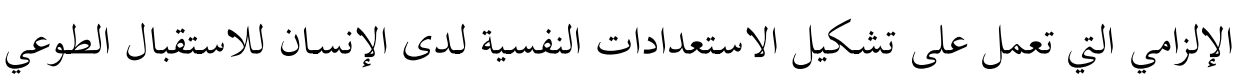

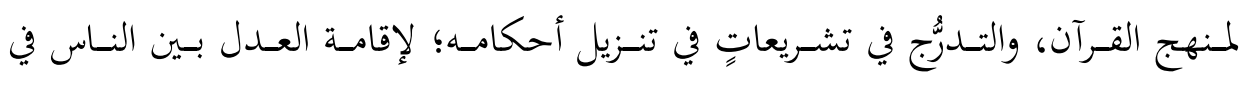

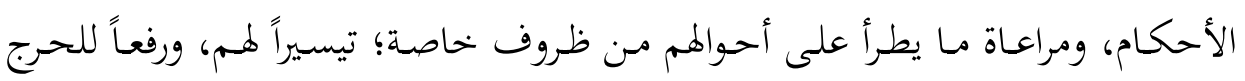

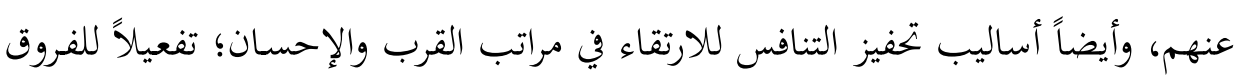

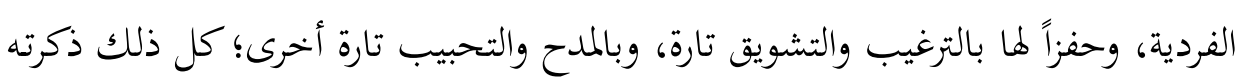
الباحثة بمنهج تحليلي اجتهدت في إيراد شواهد مناسبة له من القرآن الكريم. ثم بسطت في الفصل الرابع الكلام عن خصائص المنهج القرآي في التغيير الفردي وآثاره، وجعلت هذه الخصائص أربعاً: استقلال المنهج القرآين، ووسطيته، وجماله، وكماله.

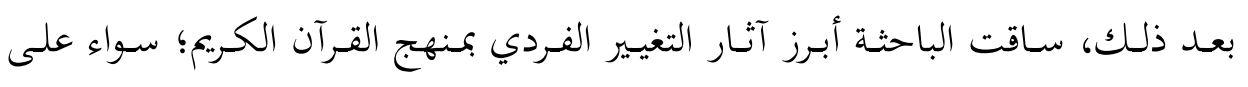

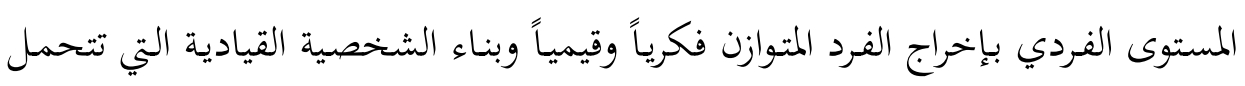

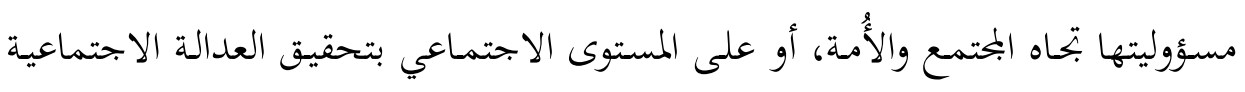

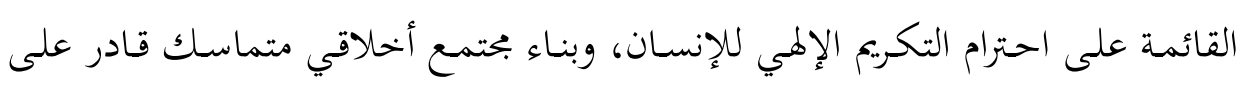
الإسهام في إعادة الأُمة الوسط إلى الوجود الحضاري لإقامة الشهادة على العالمين. وجعلدت الباحثة خاتمـة فصـول الكتـاب خامسـها بعنوان موانع التغيير الفردي في

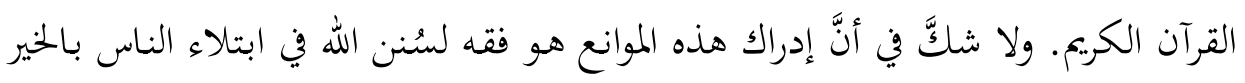

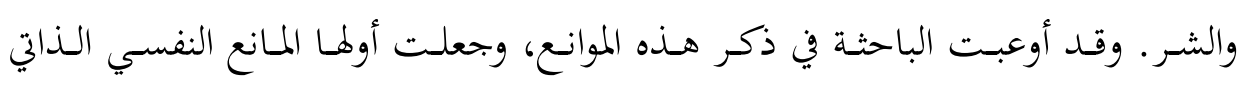

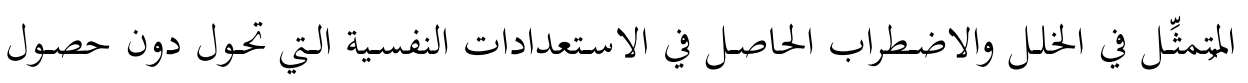

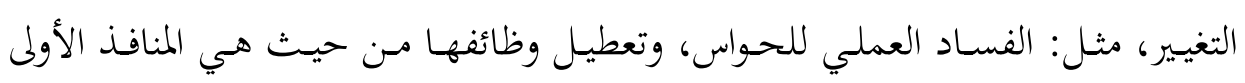

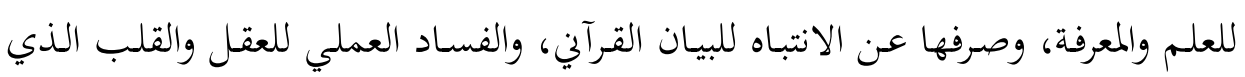
يمنع العقل من التفكير المنهجي (الشك، والظن)، ويمنع القلب من الفقه القرآين (الهوى). 
وقـــ بيَّــت الباحثـة دور الشـك والظـن في المنـع مـن الاسـتجابة العقليـة المنهجيـة

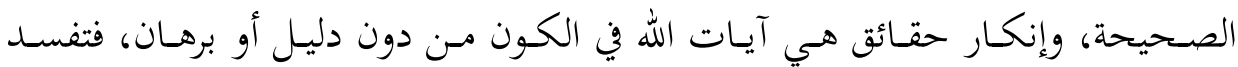

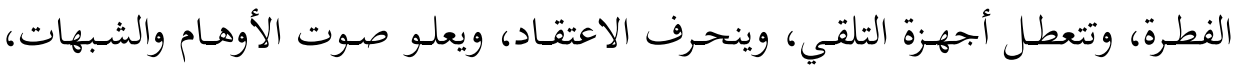
فينتج من ذلك فراغ العقل الذي هو من أكبر محركات الهوى القلبي الباعث على ونى الحيلولة

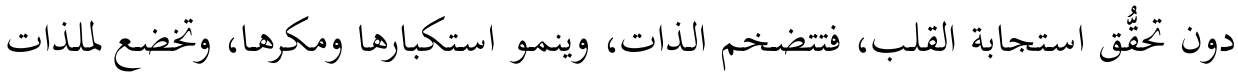

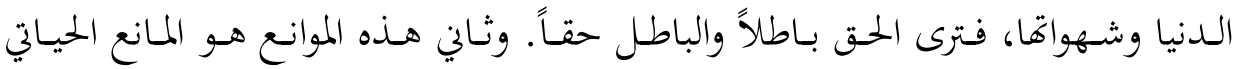

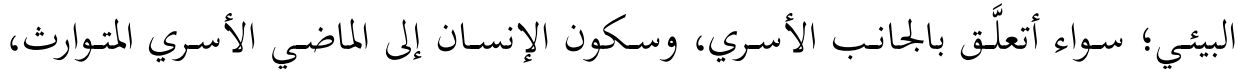

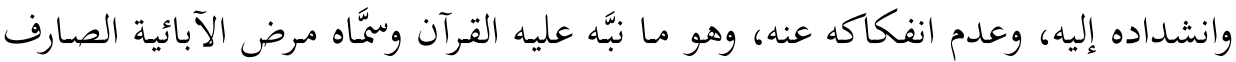

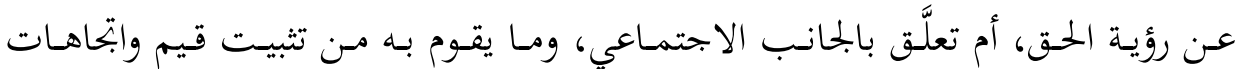

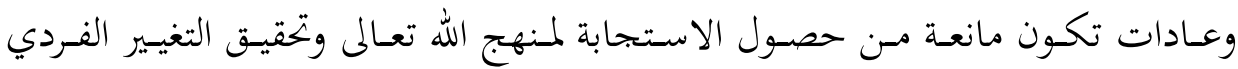
المنشود.

وأفهت المؤلِّفة كتاهـا بخاتمة ضمَّنتها أهم نتائج الدراسة، وأبرز التوصيات التي ارتأقةا ضرورية وجديرة بتوجيه النظر إليها من قِبَل الباحثين والمهتمين.

\section{تقويم الكتاب}

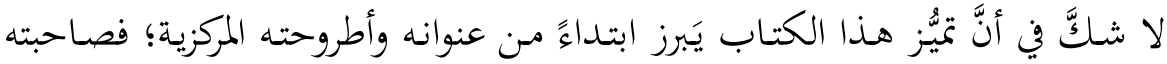

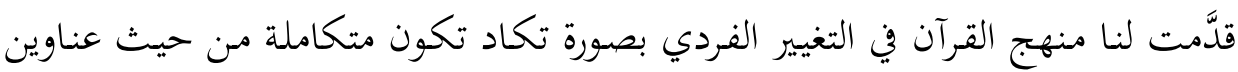

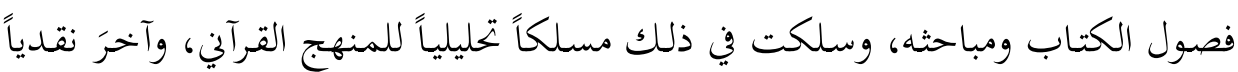

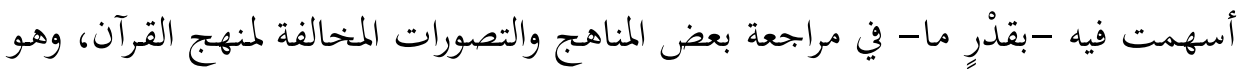

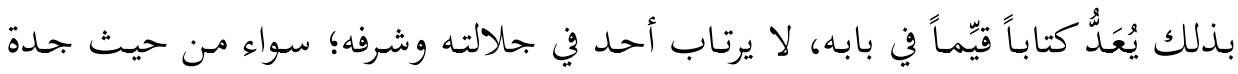
موضوعه، ودقة تناوله، وسعة مدارسته، وانفتاحسه على معارف وعلوم شتى، بتمع بين

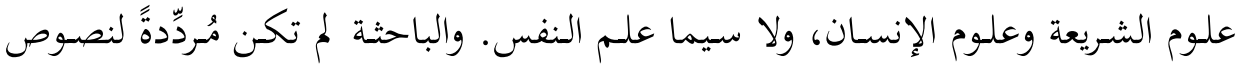

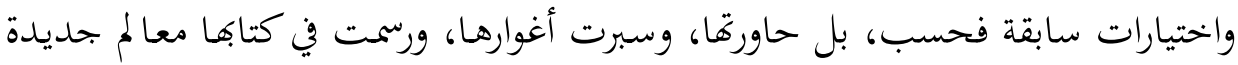

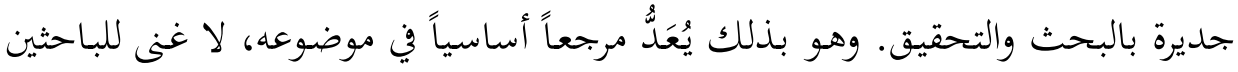
في الدراسات القرآنية ودارسي قضايا الإصلاح عن الارتواء من مَعينه. 


\section{ملاحظات منهجية ومعرفية}

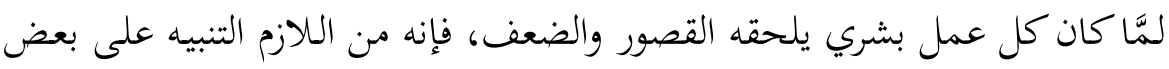

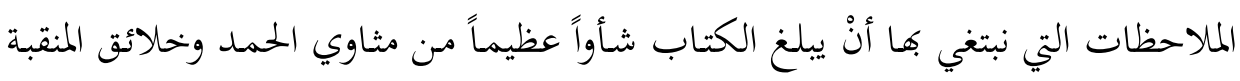

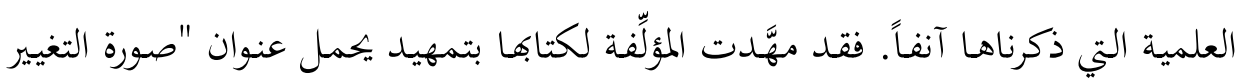

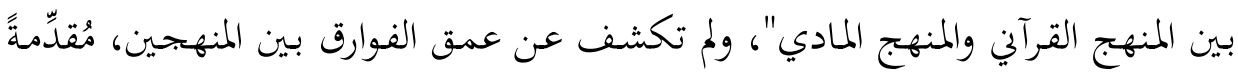

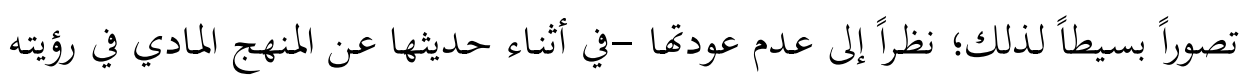

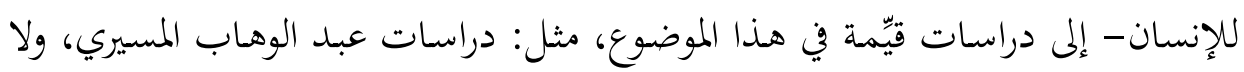

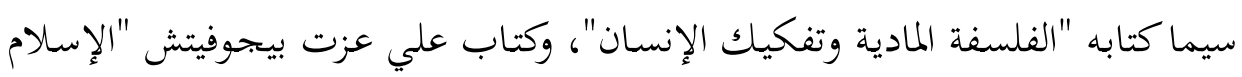

$$
\text { بين الشرق والغرب"، وكتاب طه عبدالرحمن "روح الحداثة". }
$$

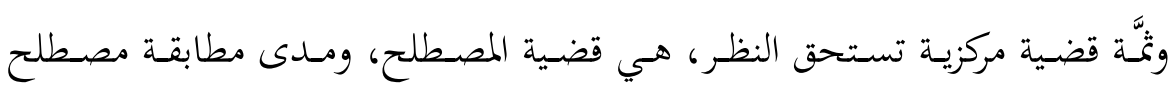
"التغيير" للدلالات التي صارت إليها الباحثة. فإذا رأت الباحثة أنَّ معنى التغيير الإيجابي

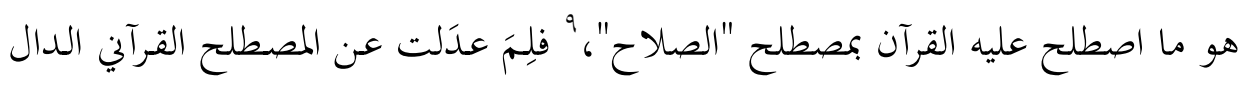

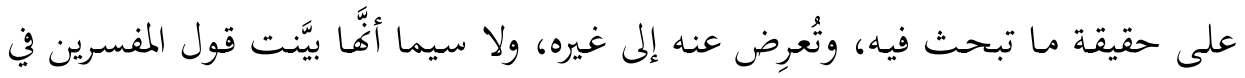

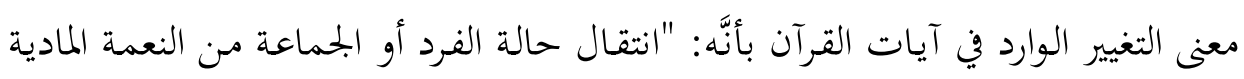

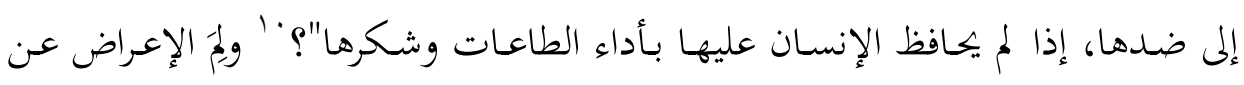

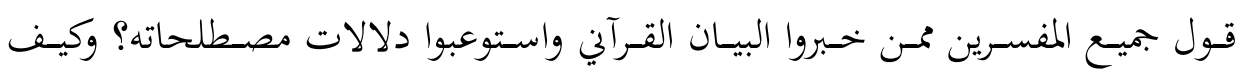

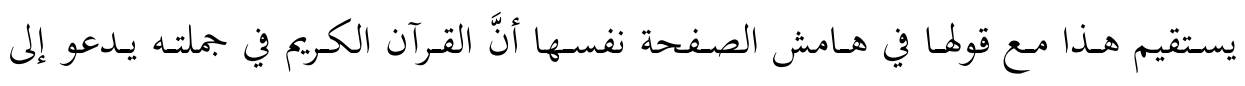

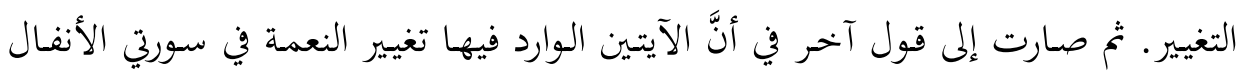

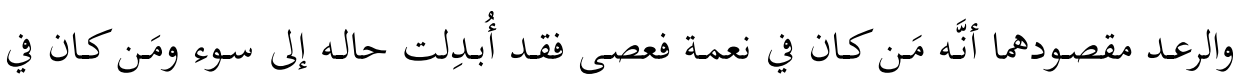

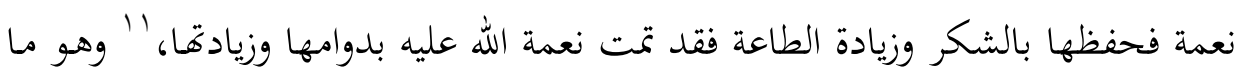

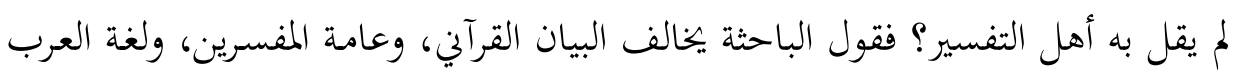

$$
\begin{aligned}
& \text { 9 المرجع السابق، ص9 ؟ . }
\end{aligned}
$$

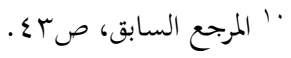

$$
\begin{aligned}
& \text { "' المرجع السابق، صهُ السابق، صعء. }
\end{aligned}
$$




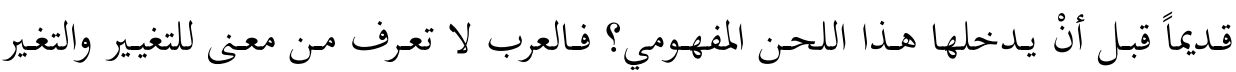

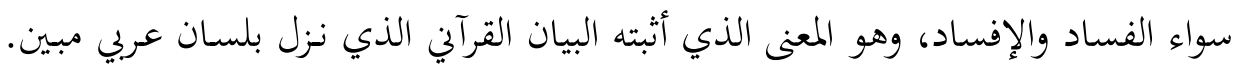

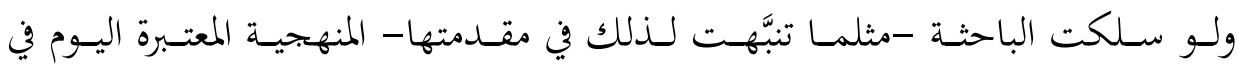
الدراسات القرآنية، وهي في تصورنا منهجية "الدراسة المصطلحية"، لفتحت أبواباً جديدةً

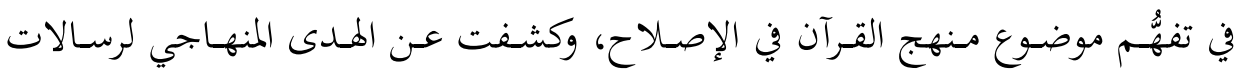

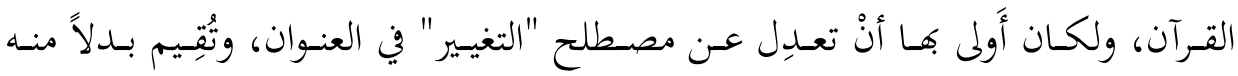

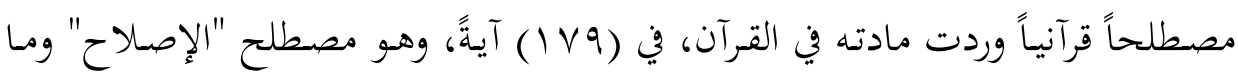

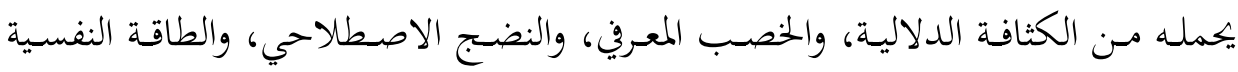
التأثيرية، والأبعاد العقدية والقِيمية والتربوية والحضارية.

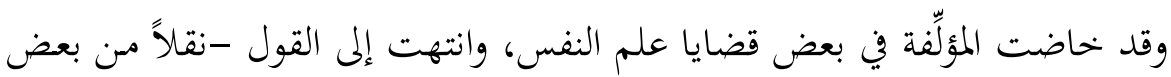

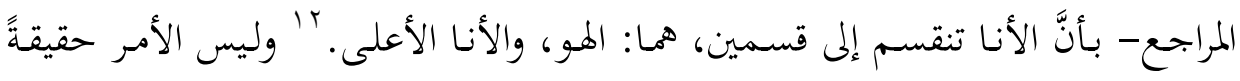

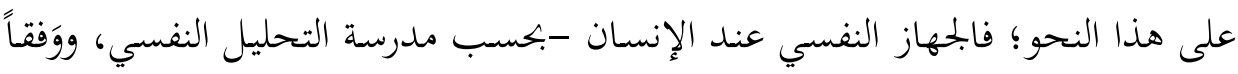

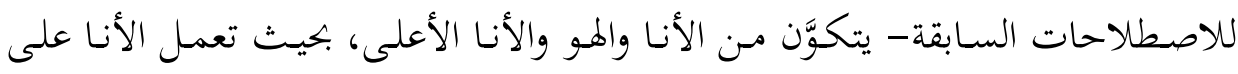

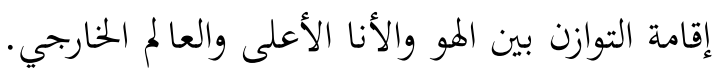

وكان للكتاب أن يغني أفكاره لو اتكأ على مراجع مهمة في هذا الموضوب، منها:

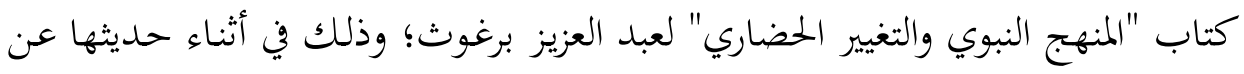

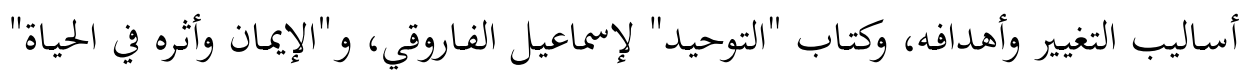

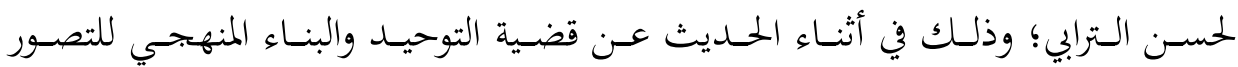

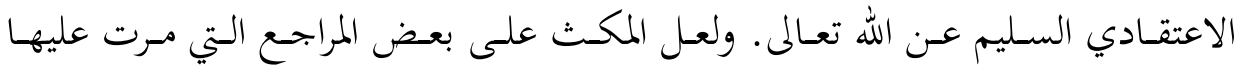

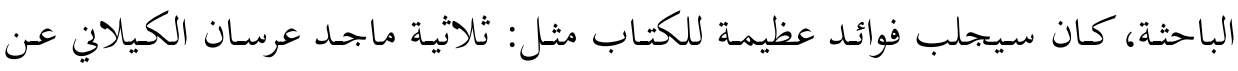

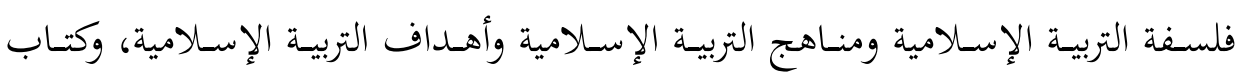

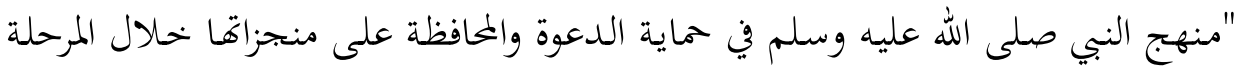

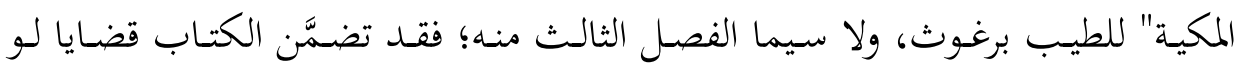


عادت إليها الباحث، واستثمرتا، وأعادت تركيبها، وانطلقت منها، لخلُصـت إلى نتائج أكثر عمقاً مما توصَّلت إليه.

ومع ذلك، فبإنَّ لسـان الكتاب بلغ مبلغه مـن الإبانة في موضوعه، الذي لا يكاد

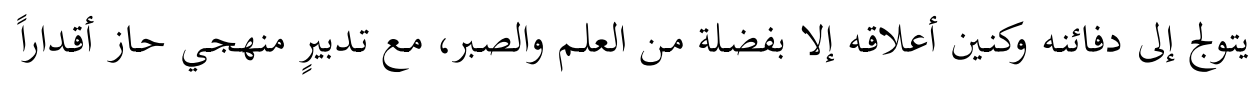

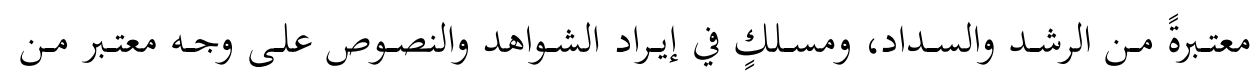

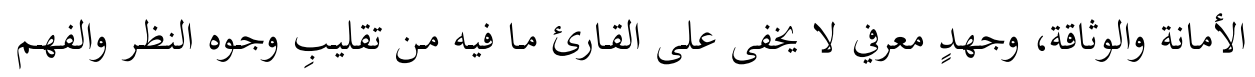

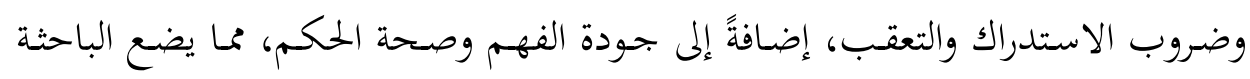

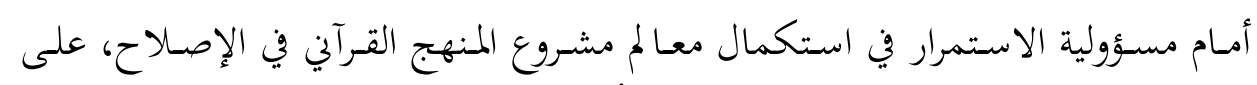
مستوى الفرد، والأسرة، والمحتمع، والدولة، والأمة. 